\title{
ASSESSMENT OF THE ECOLOGICAL STABILITY OF THE VILLAGE OF BIELOVCE AS A RESULT OF TO CHANGES IN LAND USE
}

\author{
Peter IVAN ${ }^{1}$, Tatiana CHEBEŇOVÁ ${ }^{1 *}$
}

\section{Abstract}

Globally, the human population is growing, which causes increasing demands on landscapes. Human activity significantly influences the ecological balance, especially in the negative. Ecological stability is the basis for assessments of all environmental conditions and for assessments according to new land uses. The area of interest is evaluated according to both positive and negative factors. There are many methodologies for calculating ecological stability, e.g., Muchová et al. (2009); Řeháčková - Pauditšová (2007); Kupková (2002); Stred'anský et al. (1995) and Löw et al. (1984).

The aim of this paper is to compare the works of the mentioned authors concerning the ecological stability of the district of Levice (Slovakia), specifically in the municipal cadastre region of Bielovce. The land uses of this territory have changed during some periods. We compared the state of the land uses in the years 1950, 2012 and 2014. During this period, the proportion of arable land increased, and the proportion of forest decreased. In the area of interest, the ecological stability increased, but not as significantly as we expected. The processed data were prepared in GIS.
Address

1 Department of Land and Water Management, Faculty of Civil Engineering, Slovak University of Technology in Bratislava, Radlinského 11, 81005 Bratislava, Slovakia

* Corresponding author: tatiana.chebenova@stuba.sk

\section{Key words}

- Ecological stability,

- Methodological procedures,

- Coefficient of ecological stability.

\section{INTRODUCTION}

Land use can be defined as an expression of human activity in space and time. This human impact involves historical, economic, social, and cultural potential. Changes in landscapes, which are powered by human needs, usually start with the deforestation of land. Deforestation has been identified as the fundamental reason for the loss of biodiversity. Gradestein - Sporn (2010) analysed the diversity of species of epiphytic bryophytes in different land use types in tropical Central and South America (Bolivia, Ecuador Costa Rica) and in Indonesia (Sulawesi), including natural rainforests, fallow secondary rainforests, isolated trees in pastures, and cacao agroforests. Changes in the richness of species from natural forests to their modified habi- tats varied greatly from a $0-10 \%$, loss of species in old secondary forests to $65-80 \%$ in young fallows and cacao agroforests. Gradestein - Sporn (2010) claims that the preservation of canopy cover is crucial to the conservation of biodiversity in tropical rainforests and also confirmed that the recovery of bryophyte diversity in regenerating tropical rainforests following clear cutting is a very slow process and may take more than one hundred years. Deforestation is mainly attributed to the shifting cultivation and commercial logging of timber. This has resulted in the fragmentation of landscapes. Landscape fragmentation and degradation can be mapped by remote sensing. This approach has been used in Northeast India (Roy - Tomar, 2000).

The biodiversity of dry or wet grasslands is usually on the same level (Kuzemko et al., 2014). However the pressure that results from 
human activities is real. The effect of the human exploitation of grasslands was investigated in the Hoanib River catchment, northwestern Namibia (Leggett et al., 2003). There, the effect of intensive grazing and the browsing of domestic stock and wildlife on the number of species and abundance of vegetation in the grasslands were compared. Leggett et al. (2003) concluded that between the areas of focus (bare earth, canopy cover, annual grass, perennial grass, and annual forbs) in both seasons (wet and dry), there was very little difference in the abundance and availability of vegetation regardless of land use. Lewis et al. (2014) concluded, to the contrary, that land use changes, particularly their management, causes declines and that the intensification of changes is a major driver governing changes in the functional composition and functional diversity of grasslands.

The deforestation process and exploitation of grasslands should be taken into account during the evaluation process of ecological stability (Bailey et al., 2007). A similar approach to evaluations of nature was presented in Sweden. Ihse - Lindahl (2000) inventoried and analysed the natural values of landscape elements. Their new idea was the implementation of cultural heritage values. The evaluation process they designed is based on botanical values together with long-term continuity in land use and management, which are underpinned by cultural components. Also, this process represents the overlap between natural landscape features and the technical capabilities of people. Changes in society have an important impact on the ecological balance of a region.

An ecosystem is characterized by its ability to revert to its native development; the greater this ability is, the more stable the ecosystem is. Ecological stability is a region's resilience to environmental disturbances and its ability to repeatedly regenerate. However, definitions and views on ecological stability are different, because ecological status is influenced by many factors (Belcakova, 2005; Halaj et al., 2013).

The aim of the paper is to focus on the application of known methods for the determination of the coefficient of ecological stability in the municipal cadastre region of Bielovce. We used methods according to Muchová et al. (2009), Řeháčková - Pauditšová (2007), Kupková (2002), Stredanský et al. (1995), and Löw et al. (1984).

\section{MATERIALS AND METHODS}

The municipal cadastre region of Bielovce is located in the self-governing region of Nitra in the district of Levice. It belongs to the Hontian - Poiplie region. Bielovce shares a border with the village of Šálov on the west, a border on the south with the village of Plášt'ovce, and on the northeast with the cadastral territory of Ipel'ský Sokolec. The village also shares a border with Hungary. Its first written mention dates from 1138, and the original name of the village was

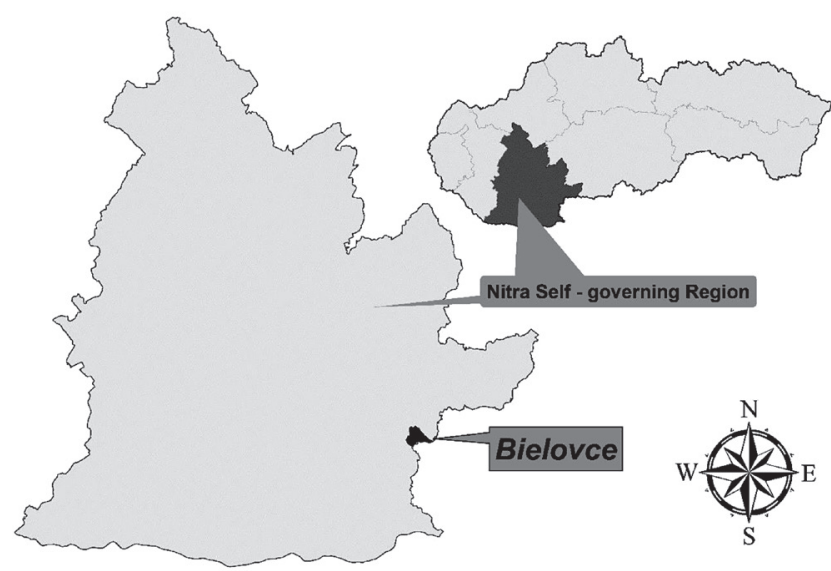

Fig. 1: The municipal cadastre region of Bielovce.
"Bela Patak". The village was a part of Hungary between years 1938 and 1945. The cadastral area of the village of Bielovee is 1137 ha with a population of 231 . The population is currently engaged in agriculture, viticulture and fishing, but was engaged in these activities more so in the past. Bielovee lies in the Ipel' uplands' and floodplain of the Ipel' River. The Ipel' River also forms Slovakia's border with Hungary. The uplands planar surface consists of younger Tertiary deposits covered by loess and loess loam. The area is deforested; acacia woodlands are the only vegetation hillsides. There is a floodplain, with alluvial black and brown soil. The territory belongs to a hot, very dry lowland region.

The development of changes in land use are captured on highly precise cadastral maps. For our purposes, we chose materials that related to the years 1950, 2012 and 2014. The map of the year 1950 is relevant to the state of the territory displayed before the advent of socialism in Slovakia. During this period, a large area around the Ipel' River featured permanent grassland and water areas; the territory in the northwest was used as arable land with meadows and a forest cover. With the advent of socialism agricultural cooperatives began to be set up, and agriculture was collectivized. At that time, balk was plowed up, and areas of arable land were merged. In the southeast of the region, the Ipel' River was modified, and the surrounding land was converted to croplands. On the northwest part of the territory, areas were standardized to permanent grasslands and arable land. There were large fields of arable land (more than $50 \mathrm{ha}$ ) utilized; these were mostly separated with ameliorative channels or plane and line stands. The main reason for this activity was to increase the efficiency and production of agricultural crops. Large blocks of arable land were created that were suitable for the use of machines, but were highly inappropriate in terms of ecological stability. Large areas of arable land have been damaged by water and wind erosion, since they were plowed up. Biodiversity has been harmed, too.

In the period from 1989 to 2012, there were no significant changes in land use in the municipal cadastral region of Bielovce. Recent trends in land use in Slovakia indicate the implementation of land consolidation projects, which were carried out between the years 2013 and 2014 in the area of interest. The changes in land use can be

\section{The changes in land use in the municipal cadastral region of Bielovee}

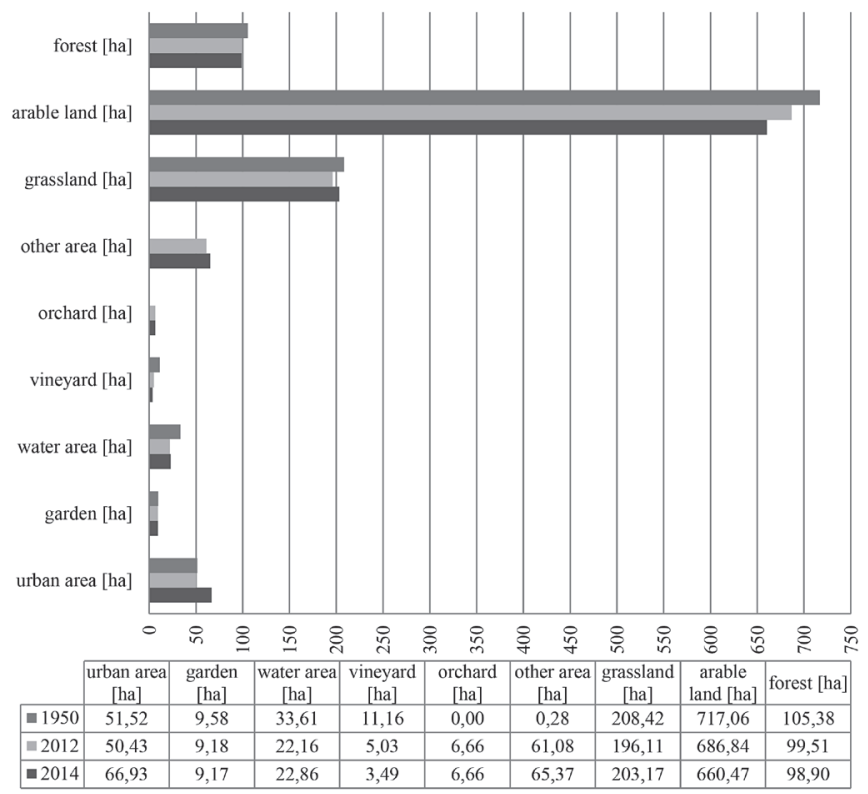

Fig. 2: The changes in land use in Bielovce's municipal cadastral territory. 


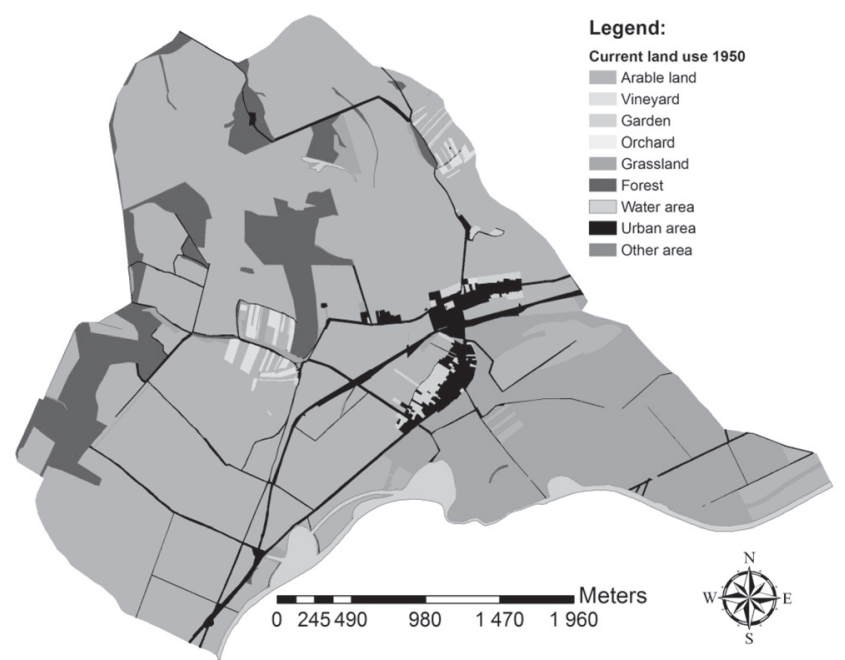

Fig. 3: The land use in 1950.

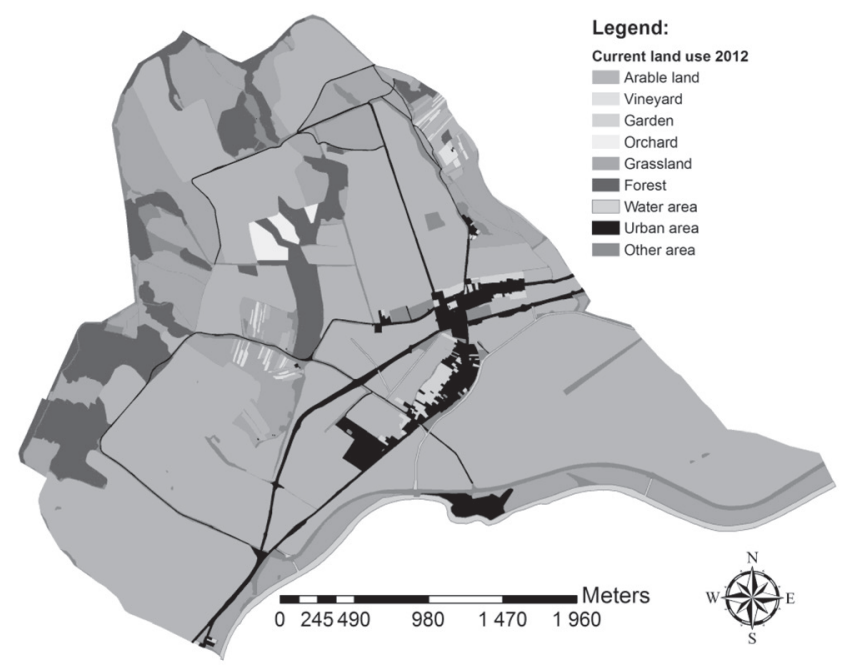

Fig. 4: The land use in 2012.

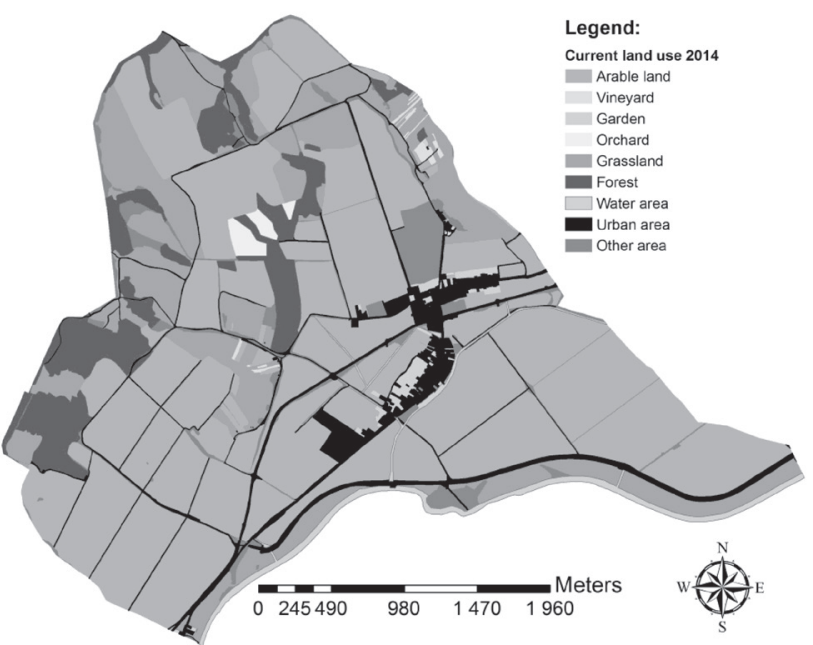

Fig. 5: The land use in 2014. seen in Figs. 3, 4, and 5.

Documents show that during the period of socialism, there was a significantly increasing trend in the volume of other areas. After the land consolidation in 2014, a slight increase was detected in other areas up to 65 ha. Also, during the socialist period, there was a higher increase in orchards up to 6 ha. A steady decrease was detected in vineyards up to 3 ha until the present. Arable land decreased to 660 ha, because of its use for non-agricultural purposes. The water areas were reduced to 22 ha and have retained this status. Gardens did not change up to 9 ha. During the reporting period, built-up areas grew to areas of 67 ha, which was caused by changes in the urban construction of a single agricultural cooperative. The areas of permanent grasslands and forests remain the same.

For our purposes, we selected five methodologies for our assessment of the ecological stability of the territory from the available literature. The individual practices represent different approaches to making an ecological assessment of the country.

The first method, Muchová et al. (2009), is also the latest methodology. This method divides the surface features of the landscape into six groups to determine the coefficient of ecological stability (CES):

$$
L C_{C E S}=\frac{P_{5}+P_{4}+P_{3}}{P_{2}+P_{1}+P_{0}}
$$

where:

$\mathrm{LC}_{\mathrm{CES}}-$ coefficient of ecological stability of the region for the purposes of land consolidation

$\mathrm{P}_{0}$ - area of land use elements classed to the 0 degree [ha]

$\mathrm{P}_{1}$ - area of land use elements classed to the $1^{\text {st }}$ degree [ha]

$\mathrm{P}_{2}-$ area of land use elements classed to the $2^{\text {nd }}$ degree [ha]

$\mathrm{P}_{3}$ - area of land use elements classed to the $3^{\text {rd }}$ degree [ha]

$\mathrm{P}_{4}$ - area of land use elements classed to the $4^{\text {th }}$ degree [ha]

$\mathrm{P}_{5}-$ area of land use elements classed to the $5^{\text {th }}$ degree [ha]

The narrative interpretation of the results:

$><0.40 \quad$ region with very low degree of ecological stability

D.41-0.80 region with low degree of ecological stability

$0.81-1.20$ region with medium degree of ecological stability

$>>1.21$ region with high degree of ecological stability

A similar methodology to the above is the methodology according to Stred'anský et al. (1995), which also compares the landscape elements of a region, but distributes the elements of the landscape into two groups.

$$
C E S=\frac{\sum_{1}^{n} A L E_{\text {Stable }}}{\sum_{1}^{n} A L E_{\text {Unstable }}}
$$

where:

$$
\begin{aligned}
& \text { CES } \\
& \text { ALE } E_{\text {Stable }} \quad \text { - coefficient of ecological stability of a region } \\
& \text { ALE } E_{\text {Unstable }} \text { - summary area of the stable elements of land use [ha] } \\
& \text { use [ha]. }
\end{aligned}
$$

The narrative interpretation of the results:

$><0.50 \quad$ significantly unstable landscape

$>0.51-1.00$ unstable landscape

$>1.01-3.00$ medium stable landscape

$>3.01-4.50$ stable landscape

$>>4.51 \quad$ significantly stable landscape

In contrast, the methodology according to Řeháčková - Pauditšová (2007) focuses on assigning values to the parameters of the 
ecological stability of the region-specific elements. Consequently, the numerical strength of the ecostabilizing abilities of the landscape elements is determined. The sum of all these values determines the resulting coefficient of ecological stability. In the calculations, the methodology takes into account the size of each element in the current landscape structure and its degree of ecological stability.

$$
C E S=\sum_{1}^{n} \frac{p_{i} \cdot S_{i}}{p}
$$

where:

$C E S$ - coefficient of ecological stability

$p_{i} \quad$ - total area for the chosen type of landscape structure [ha]

$S_{i} \quad$ - degree of ecological stability designed for the chosen type of landscape structure

$p \quad$ - total surface area of the area of interest [ha]

$n-$ number of landscape elements in the area of interest.

The narrative interpretation of the results:

$>1.00-1.49$ very low degree of ecological stability

$>1.50-2.49$ low degree of ecological stability

$>2.50-3.49$ medium degree of ecological stability

$>3.50-4.49$ high degree of ecological stability

$>4.50-5.00$ very high degree of ecological stability.

A different way of assessing the ecological stability is the methodology according to Kupková (2001). This method is based on an evaluation of the effect of the anthropogenic landscape. The ratings are generated by dividing the landscape elements into 7 categories.

$$
C A I=\frac{(A L+U A+O A)}{(G a+G r+V i+O r+F o+W A)}
$$

$$
\begin{array}{ll}
C A I & \text { - CES of region } \\
A L & \text { - arable land [ha] } \\
U A & \text { - urban area [ha] } \\
O A & \text { - other area [ha] } \\
G a & \text { - garden [ha] } \\
G r & \text { - grassland [ha] } \\
V i & \text { - vineyard [ha] } \\
O r & \text { - orchard [ha] } \\
F O & \text { - forest [ha] } \\
W A & \text { - water area [ha] }
\end{array}
$$

The narrative interpretation of the results:

$><1.00$ predominance of natural landscape elements

$>=1.00$ balanced landscape

$>>1.00$ predominance of anthropogenic landscape elements.

Löw et al. (1984) are focused on the percentage comparison of areas with specific coefficients for each category. The narrative score of the results is similarly characterized as a range of human interventions into the landscape.

$$
C E S=\frac{1.5 A+B+0.5 C}{0.2 D+0.8 E}
$$

where:

$C E S$ - coefficient of ecological stability

$A \quad-\%$ of acreage of $5^{\text {th }}$ degree of ecological stability (forest)

$B \quad-\%$ of acreage of $4^{\text {th }}$ degree of ecological stability (water area)

$C-\%$ of acreage of $3^{\text {rd }}$ degree of ecological stability (grassland)

$D-\%$ of acreage of $2^{\text {nd }}$ degree of ecological stability (arable land)

$E-\%$ of acreage of $1^{\text {st }}$ degree of ecological stability (urban area).

The narrative interpretation of the results:

$><0.10 \quad$ degraded landscape

$>0.10-01.00$ disturbed landscape

$>=01.00 \quad$ balanced landscape

$>1.00-10.00$ landscape with predominance of natural landscape elements

$>>10.00 \quad$ natural landscape.

\section{RESULTS}

The coefficient of ecological stability was calculated for a selected year according to five different methodologies. The results also include the narrative interpretation of the results. The results are shown in the graphs in Figure 6 and Table 1.

\section{The changes in the values of the coefficients over time}

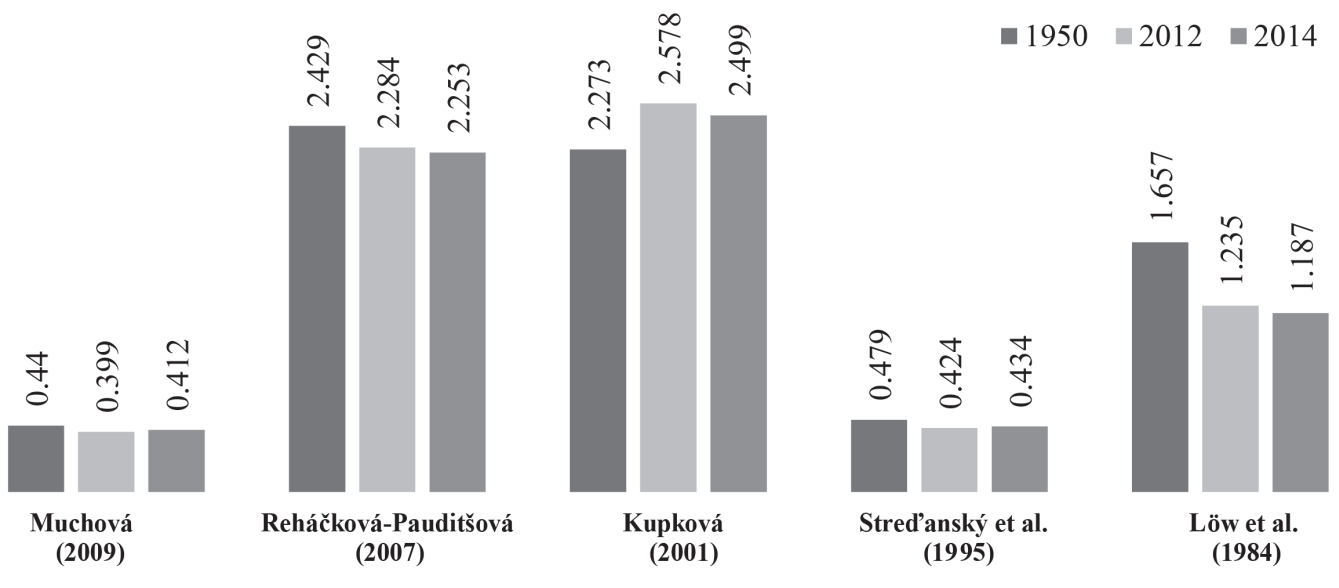

Fig. 6: The changes in the values of the coefficients over time (graph). 
Tab. 1: The development of the coefficients in a table.

\begin{tabular}{|l|c|c|c|l|}
\hline \multirow{2}{*}{ Methodology according to: } & \multicolumn{3}{|c|}{ Year } & Evaluation of ecological status according to each methodology \\
\hline \multirow{2}{*}{ Muchová (2009) } & $\mathbf{1 9 5 0}[-]$ & $\mathbf{2 0 1 2}[-]$ & $\mathbf{2 0 1 4}[-]$ & \\
\hline Reháčková-Pauditšová (2007) & 0.44 & & 0.412 & low degree of ecological stability \\
\cline { 2 - 6 } & & 0.399 & & very low degree of ecological stability \\
\hline Kupková (2001) & 2.429 & 2.284 & 2.253 & low degree of ecological stability \\
\hline Stred'anský et al. (1995) & 0.479 & 0.424 & 0.434 & significantly unstable landscape \\
\hline Löw et al. (1984) & 1.657 & 1.235 & 1.187 & predominance of natural elements \\
\hline
\end{tabular}

\section{CONCLUSIONS}

The development of changes in the composition of landscape elements in our research was focused on the last 70 years. The methodology according to Muchová et al. (2009), noted a deterioration of ecological stability in the period of socialism, but also noticed an increase due to the execution of a consolidation project. The methodology change did not affect the narrative interpretation of the results according to changes in land use. The methodology according to Stred'anský et al. (1995) showed similar numerical changes. This method of evaluating a region is considered as a global method for evaluating large landscape areas. In contrast, the method according to Řeháčková Pauditšová (2007) shows a continuous decrease in the ecological stability of the territory from the year 1950 until the present. Another case is demonstrated through the methodology according to Kupková (2001) and Löw et al. (1984), which describes the extent of the anthropogenic impact on a landscape. The calculations according to Kupková (2001) describe a region with predominantly anthropogenic elements. The coefficient of the anthropogenic influence on the country confirmed the useful purposes of consolidation projects. On the contrary, the results according to Löw et al. (1984) suggest a continuing decrease in ecological stability. The methodologies did not reveal a significant difference between the assumed higher ecological stability of the year 1950 and the lower ecological stability of the year 2012, which could be caused by the assumption that arable land has a destabilizing effect on ecological stability. This assumption is based on the use of chemical preservatives, artificial fertilizers and heavy machinery. This may have been justified in the period of socialism, but not in the years before the year 1950. The ambiguity of the results also can be explained by the fact that the land use data from 1950 can be disputed. Land consolidation projects are designed to improve the ecological stability of a territory; however, that cannot always be achieved. In the area of interest, there was an improvement in ecological stability. It was not so significant for all the methodologies to take it into account in the narrative interpretation of the results. The analysis confirms the stable position of certain landscape elements. The results have sparked a debate about the pros and cons of the methodologies used.

\section{Acknowledgements}

This work was financially supported by Projects VEGA 1/0625/15 and VEGA 1/0665/15. 


\section{REFERENCES}

Bailey et al. (2007) Integrating stream bioassessment and landscape ecology as a tool for land use planning. In: Freshwater Biology. Vol. 52, No. 5, pp. 908-917, ISSN: 0046-5070.

Belcakova, I. (2005) Morava - Slovak Part. In: Border-Free River Basins. Flusslandschaften ohne Grenzen. Mitteleuropäische Ansätze zur Entwicklung vom Flusslandschaften und Förderung landschaftsbezogener Identität. - Bratislava : Road. - ISBN 8088999-28-6. - pp. 126-142

Gradstein, S. Robert - Sporn, S. Goda (2010) Land-use change and epiphytic bryophyte diversity in the tropics. In: Nova Hedwigia. Supplement: 138, pp. 311-323, ISSN: 0029-5035.

Halaj, P. et al. (2013) Effect of catchment land use on hydromorphological status of streams in agricultural land. In Water resources. Forest, marine and ocean ecosystems. 1st ed. 889 pp. ISBN 978619-7105-02-5. International multidisciplinary scientific geoconference SGEM. Sofia : STEP92 Technology, 2013, pp. 117-124.

Ihse, M - Lindahl, C. (2000) A holistic model for landscape ecology in practice: the Swedish survey and management of ancient meadows and pastures. In: Landscape and Urban Planning. Vol. 50, Nos. 1-3, pp. 59-84, ISSN: 0169-2046.

Kupková, L. (2001) Land use as indicator of the anthropogenic impact on the landscape. Land use/land cover changes in the period of globalisation. Prague: Proceedings of the IGU -LUUC International Conference Prague, 2001.133-143 pp.

Kuzemko et al. (2014) Dry grassland vegetation of Central Podolia (Ukraine) - a preliminary overview of its syntaxonomy, ecology and biodiversity. In: Tuexenia. No. 34, pp. 391-430, ISSN: 0722494X.
Leggett et al., (2003) Does land use matter in an arid environment? A case study from the Hoanib River catchment, north-western Namibia. In: Journal of Arid Environments. Vol. 53, No. 4, pp. 529-543, ISSN: 0140-1963.

Lewis et al. (2014) Inferring temporal shifts in land use intensity from functional response traits and functional diversity patterns: a study of Scotland's machair grassland. In: Oikos. Vol. 123, No. 3, pp. 334-344, ISSN: 0030-1299.

Löw J. et al. (1984) Principles for defining and designing a territorial system of ecological stability in land-use planning practice. Agroprojekt Brno, 55 pp.

Muchová, Z. et al., (2009) Methodological standards of design of land consolidation. $1^{\text {st }}$. edition. Nitra : Slovak University of Agriculture in Nitra in partnership with the Ministry of Agriculture and Rural Development of the Slovak Republic, 2009. 554 pp. ISBN 978-8-552-0267-9

Rehačková, T. - Pauditšová, E. (2007) Methodical procedure to calculate the coefficient of ecological stability. In Acta environmentalica universitatis comenianae, Bratislava, Vol. 15, No. 1. 2007. pp. 26-38. ISSN 1335-0285

Roy, P. S. - Tomar, S. (2000) Biodiversity characterization at landscape level using geospatial modelling technique. In: Biological Conservation. Vol. 95, No. 1, pp. 95-109, ISSN: 0006-3207.

Stred'anský, J. et al. (1995) Landscaping. Nitra : VŠP. 104 pp, ISBN 80-7137-224-2.

Zaušková, L'. and Midriak, R. 2007. Carrying capacity and land use. Banská Bystrica: UMB Banská Bystrica, FPV, 70 pp. 